\title{
Mineração
}

\section{Caracterização da parcela magnética de minério fosfático de carbonatito}

\author{
(Characterization of the magnetic phase from \\ carbonatitic phosphate ore)
}

Alysson A. Borges

Engenheiro de Minas - Pedreira Um Valemix Ltda. Mestrando do Programa de Pós-Graduação em Engenharia Mineral -UFOP.E-mail: alysson@pedreiraum.com.br

José Aurélio Medeiros da Luz

Professor Adjunto do Departamento de Engenharia de Minas. Universidade Federal de Ouro Preto

E-mail: jaurelio@demin.ufop.br

Eliomar Evaristo Ferreira

Doutor em Engenharia Metalúrgica - Companhia Vale do Rio Doce- Santa Luzia - MG

E-mail:eliomar.ferreira@cvrd.com.br

\section{Resumo}

O rejeito magnético do Complexo Mineração de Tapira, Tapira - MG, onde se processa rocha fosfática, foi estudado. Suas principais características físicas, químicas e mineralógicas foram determinadas, assim como suas respostas a processos de concentração. A primeira etapa do trabalho envolveu análise granulométrica, análise química, difratometria de raios X, espectroscopia Mössbauer, microscopia ótica e microscopia eletrônica de varredura. Na segunda etapa, ensaios de separação magnética, flotação e lixiviação ácida foram realizados. O material sob estudo revelou-se composto essencialmente por magnetita, hematita (martita) e ilmenita. A separação magnética resultou em recuperação metalúrgica de ferro acima de 96 \%. Sabão sódico de ácido graxo vegetal (Hidrocol) deu melhores resultados no processo de flotação, comparado ao desempenho de amina, quando empregados como coletores de silicatos e apatita, visando à depuração dos minerais portadores de ferro. A atrição preliminar ao condicionamento não influenciou sensivelmente a flotação. Os ensaios de lixiviação visaram a eliminação de fósforo, contaminante crítico nos minérios de ferro. O ácido acético extraiu 0,41 \% do fósforo presente, enquanto o ácido clorídrico extraiu em torno de 73 \% do fósforo. Estudos ulteriores de otimização de tais ensaios são recomendados, buscando o uso do material sob estudo em siderurgia.

Palavras-chave: Caracterização tecnológica, minério de ferro, magnetita.

\begin{abstract}
The characterization of the magnetic fraction of a tail from phosphate rock processing was done. Samples were from Tapira, in Minas Gerais, Brazil. The main physical, chemical and mineralogical properties, as well as this material response to separation processes were determined. The first part of this work encompasses the mineralogical characterization (determination of particle size distribution, X-ray diffraction, Mössbauer spectroscopy, optical microscopy and scanning electron microscopy). In the second part, concentration tests by magnetic separation, flotation and acid leaching were carried out. The iron-bearing material is composed predominantly of magnetite, hematite and ilmenite. Wet low intensity magnetic separation has reached iron recovery above $96 \%$. As far as flotation is concerned, fatty acid soap from vegetal oil (Hidrocol) as a collector for silicates and apatite was better than amine. Attrition or scrubbing prior to conditioning seems not to affect flotation performance in this case. Acetic acid has extracted only $0.41 \%$ of the phosphorus, and hydrochloric acid has depleted $73.05 \%$ of the phosphorus in the samples under leaching.
\end{abstract}

Keywords: Technological characterization, iron ore, magnetite, phosphate rock. 


\section{Introdução}

A caracterização tecnológica de minérios é ferramenta importante no aproveitamento de um recurso mineral de forma otimizada, sendo recomendada nas fases de exploração e explotação de um bem mineral.

A caracterização, até bem pouco tempo, era pouco aplicada a rejeitos de usinas de beneficiamento de minérios, sendo esses descartados sem maiores conhecimentos de suas características físicas, químicas e mineralógicas e de sua resposta a processo de refino. Nos últimos anos, isto vem mudando, não só pela maior preocupação com questões ambientais, como também, em alguns casos, devido à escassez do minério e à depleção de reservas, com a conseqüente diminuição dos teores das minas.

O conhecimento dos rejeitos favorece à viabilização de seu ulterior aproveitamento como subproduto na própria usina, ou em outro segmento industrial. Viabilizando-se seu reuso, minimiza-se o impacto ambiental e cria-se receita, onde antes havia despesas.

Dentro desse contexto, esse trabalho apresenta a caracterização tecnológica do rejeito magnético produzido no Complexo Mineração de Tapira, Tapira - MG. Por seu uso corrente no meio industrial, o presente trabalho adota o termo carbonatito, como sinônimo de intrusão de domo alcalino de rocha carbonática com ocorrência de minerais fosfáticos.

\section{Materiais e métodos}

O trabalho constou de duas etapas distintas: a primeira etapa envolveu caracterização mineralógica dessa parcela magnética, aqui denominada de rejeito magnético (análise granuloquímica, difratometria de raios $\mathrm{X}$, microscopia ótica e microscopia eletrônica de varredura) e a segunda envolveu ensaios de concentração física, físico-química, bem como de lixiviação ácida.

Amostra de 112 kg do material foi homogeneizada sucessivamente em pilha longitudinal em chevron, com retomada transversal, até obtenção de 8 alíquotas de $14,5 \mathrm{~kg}$. A partir de uma das alíquotas, obtiveram-se amostras representativas para análise granulométrica, análise química, difratometria de raios X, espectroscopia Mössbauer e, também, amostras para confecção de lâminas delgadas polidas, empregadas nos estudos via microscopia ótica e microscopia eletrônica de varredura.

Para a análise granulométrica, foram empregadas peneiras da série da ABNT entre $500 \mu \mathrm{m}$ e $37 \mu \mathrm{m}$. Uma alíquota de cada faixa granulométrica foi retirada para análise química.

Uma determinação mineralógica preliminar foi efetuada por difratometria de raios X executada em difratômetro Shimadzu, modelo XRD-6000, com filtro de ferro e tubo de cobalto, sendo que a varredura da amostra foi feita de $20^{\circ}$ a $70^{\circ}$, com velocidade de $2^{\circ}$ por minuto.
A microscopia ótica auxiliou na identificação dos minerais presentes. Foi feita contagem de pontos, a fim de se determinar o teor volumétrico dos minerais de ferro e titânio presentes na amostra. Naturalmente, o cruzamento das informações da análise química com as propriedades típicas dos minerais servia de suporte, em todas as instâncias de determinação mineralógica. Fez-se, também, microssondagem em consórcio microscopia eletrônica de varredura (MEV-EDS), com o intuito de se rastrear o modo de associação do fósforo, ou seus compostos, na amostra em estudo.

A determinação do estado de oxidação do ferro foi realizada por espectrometria Mössbauer, o que possibilitou quantificar os minerais de ferro na amostra (magnetita, hematita e ilmenita).

A separação magnética de baixa intensidade, com corrente de 2,0 amperes, foi utilizada, tratando-se, polpa com $20 \%$ de sólidos em massa. Ensaios de flotação foram feitos utilizandose amido de milho como depressor dos minerais de ferro (500 g/t) e, como coletor, óleo vegetal (Hidrocol) saponificado sob dosagem $350 \mathrm{~g} / \mathrm{t}$; ou amina (EDA-3, da Clariant), sob dosagem de 100 g/t. Alternativamente, a atrição da polpa antes do condicionamento foi tentada. Em relação à lixiviação ácida, fez-se passar pela amostra soluções de ácido acético e ácido clorídrico, a fim de se extrair o fósforo.

\section{Resultados e discussão 3.1 Caracterização tecnológica}

\subsubsection{Análise granulométrica}

A Figura 1 apresenta a análise granulométrica do material, com $\mathrm{d}_{80}=0,42 \mathrm{~mm}$ (80\% da amostra passante em $420 \mu \mathrm{m}$ ).

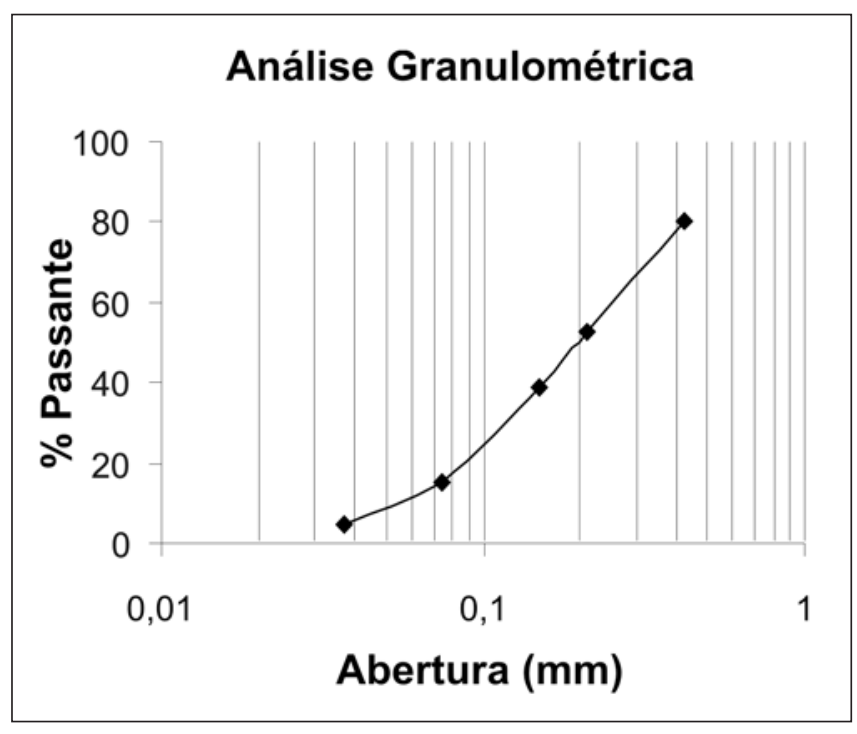

Figura 1 - Análise granulométrica do rejeito magnético de Tapira. 
Análise de regressão dos dados indicou boa aderência à seguinte distribuição de Rosin-Rammler (coeficiente de correlação de 99,51 \%):

$Y_{\text {pass }}=1-\exp \left[\ln (1 / 2) \times\left(\frac{d_{i}}{d_{50}}\right)^{m}\right]=1-\exp \left[-0,6931\left(\frac{d_{i}}{0,21}\right)^{1,28}\right]$

Onde:

$\boldsymbol{Y}_{i c}$ - fração passante do material na classe granulométrica i [-].

$\boldsymbol{d}_{\boldsymbol{i}}$ - tamanho da classe granulométrica $\boldsymbol{i}[\mathrm{mm}]$.

$\boldsymbol{d}_{50}$ - tamanho médio (50 \% passante) [mm].

$\boldsymbol{m}$ - agudez da distribuição [-].

\subsubsection{Análise química}

A Tabela 1, a seguir, apresenta os resultados da análise química, por faixa granulométrica.

Vê-se, pela Tabela 1, que o ferro tende a se concentrar nas frações mais finas. $\mathrm{O}$ alto teor desse elemento, a princípio, sugere aplicação deste na indústria siderúrgica. Em contrapartida, contrariamente a essa diretriz, tem-se a presença de $\mathrm{P}_{2} \mathrm{O}_{5}$, em concentrações que, quando comparadas à especificação típica de minério de ferro (teor de $\mathrm{P}<0,040 \%$ ), são exorbitantes. Isso já era esperado, pois se trata de um rejeito de um processo industrial de concentração de minério essencialmente apatítico.

Outro ponto a se destacar é a presença de titânio, expresso na forma de $\mathrm{TiO}_{2}$. A presença de titânio em minérios de ferro contribui pra a melhora da qualidade do aço inox. Entretanto, para aplicação em processo de fabricação de aço em fornos elétricos, o titânio tem influência negativa na consumo de energia, além de diminuir a vida útil dos refratários.

$\mathrm{A} \mathrm{SiO}_{2}, \mathrm{MgO}$ e CaO estão em proporções bem mais próximas às especificações de mercado de minérios de ferro para a utilização siderúrgica.

A aplicação desse rejeito industrial diretamente na metalurgia, sem processamento adicional, como um agregado ao minério hematítico, deve ser descartada, não só pela maior dificuldade de se trabalhar a magnetita nos processos siderúrgicos, como também devido ao elevado teor de fósforo presente. Resolvendo-se o problema da contaminação por fósforo, uma aplicação siderúrgica de sucesso seria em processos de aglomeração, nomeadamente na sinterização e pelotização, pois a reação de oxidação de magnetita para hematita é exotérmica (Cloud \& Manuel, 2003; Zuluaga, 2002; Yang, 1997), resultando, para os processos citados, ganhos energéticos típicos de 30 $\%$ (economicamente muito atrativos).

\subsubsection{Difratometria de Raios X}

A análise difratométrica da amostra revelou a presença dos seguintes minerais: magnetita, hematita e ilmenita. Sendo assim, o ferro detectado, na análise química, é proveniente da magnetita e da hematita, ao passo que o titânio é proveniente da ilmenita.

\subsubsection{Espectroscopia Mössbauer}

A espectroscopia Mössbauer possibilitou a quantificação das fases minerais portadoras do ferro, a qual é assim distribuída: magnetita: 69 \%; hematita: $23 \%$; ilmenita: $6 \%$.

\subsubsection{Microscopia Ótica}

Os estudos de microscopia ótica foram realizados com principal foco nos minerais portadores do ferro. Com o

Tabela 1 - Análise química percentual.

\section{Análise Química}

\begin{tabular}{c|c|c|c|c|c|c|c|c}
\hline Abertura mm & \% ret simples & $\mathbf{P}_{\mathbf{2}} \mathbf{O}_{\mathbf{5}}$ & $\mathrm{Fe}_{\mathbf{T}}$ & $\mathbf{M g O}$ & $\mathrm{CaO}$ & $\mathrm{TiO}_{\mathbf{2}}$ & $\mathrm{Al}_{\mathbf{2}} \mathrm{O}_{\mathbf{3}}$ & $\mathrm{SiO}_{\mathbf{2}}$ \\
\hline 0,420 & 20,00 & 1,57 & 74,4 & 2,27 & 2,2 & 11,23 & 1,02 & 3,46 \\
\hline 0,210 & 27,50 & 2,21 & 73,06 & 2,03 & 3,07 & 10,38 & 0,85 & 3,55 \\
\hline 0,149 & 13,83 & 2,16 & 77,37 & 1,76 & 2,94 & 9,36 & 0,61 & 2,65 \\
\hline 0,074 & 23,33 & 1,76 & 79,59 & 1,66 & 2,27 & 8,61 & 0,64 & 2,63 \\
\hline 0,037 & 11,00 & 1,58 & 78,9 & 1,67 & 2,12 & 7,98 & 0,67 & 2,41 \\
\hline$-0,037$ & 4,33 & 1,53 & 80,63 & 1,68 & 2,12 & 7,83 & 0,83 & 2,57 \\
\hline
\end{tabular}


objetivo de permitir uma comparação com estudos anteriores do material de Tapira, trabalhou-se, principalmente, com luz transmitida, embora a técnica de luz refletida seja amplamente usada para esse tipo de minerais. Assim, seções polidas delgadas foram confeccionadas, por faixa granulométrica.

O exame microscópico permitiu detectar que a magnetita, a qual apresenta aspecto rosado, encontra-se em fase martitização, processo pelo qual a magnetita transforma-se pseudomorficamente em hematita. Esse processo evolui das bordas para o centro do grão. A ilmenita, na maioria das vezes, apresenta-se lamelar e intercrescida nos grãos da magnetita, fator que dificultará expressivamente eventual concentração seletiva dos dois minerais em escala industrial. As Figuras 2 e 3 mostram a visualização de tal descrição.

Estimativas do teor volumétrico também foram feitas por microscopia ótica, para todas as todas as faixas granulométricas. Para tanto, adotou-se o método de se tomar espaçamentos transversais e longitudinais constantes no percorrer da lâmina.

A seguir, na Tabela 2, estão apresentados os resultados obtidos nessa fase do trabalho.

Portanto, através dessa estimativa, nota-se que há uma concentração dos minerais portadores de ferro nas frações mais finas. Ressalte-se que o resultado dessa técnica, embora sofra influência direta do operador, fornece boa estimativa, compatível com os resultados obtidos por análise química.

\subsubsection{Microscopia eletrônica de varredura}

A microscopia eletrônica foi usada para se estudar o modo de ocorrência do elemento fósforo, averiguando a hipótese de associação intrínseca com os minerais portadores de ferro (no interior dos grãos), ou adsorção sobre a superfície dos mesmos (nos contornos dos grãos).
A seguir, uma elétron-micrografia de partícula típica é apresentada. Inicialmente, uma análise geral dessa partícula foi feita e, posteriormente, análises nas bordas demarcadas na Figura 4. Além da predominância de ferro, o que já era esperado, destaca-se a presença do titânio. Já o fósforo não foi detectado. De modo geral, a microscopia eletrônica e a microssondagem confirmaram quais os minerais e elementos estão presentes e indicaram que o fósforo não está estruturalmente associado aos minerais portadores do ferro (ocorrendo como apatita). A microssondagem trouxe, como novidade, a presença dos elementos de terras-raras.

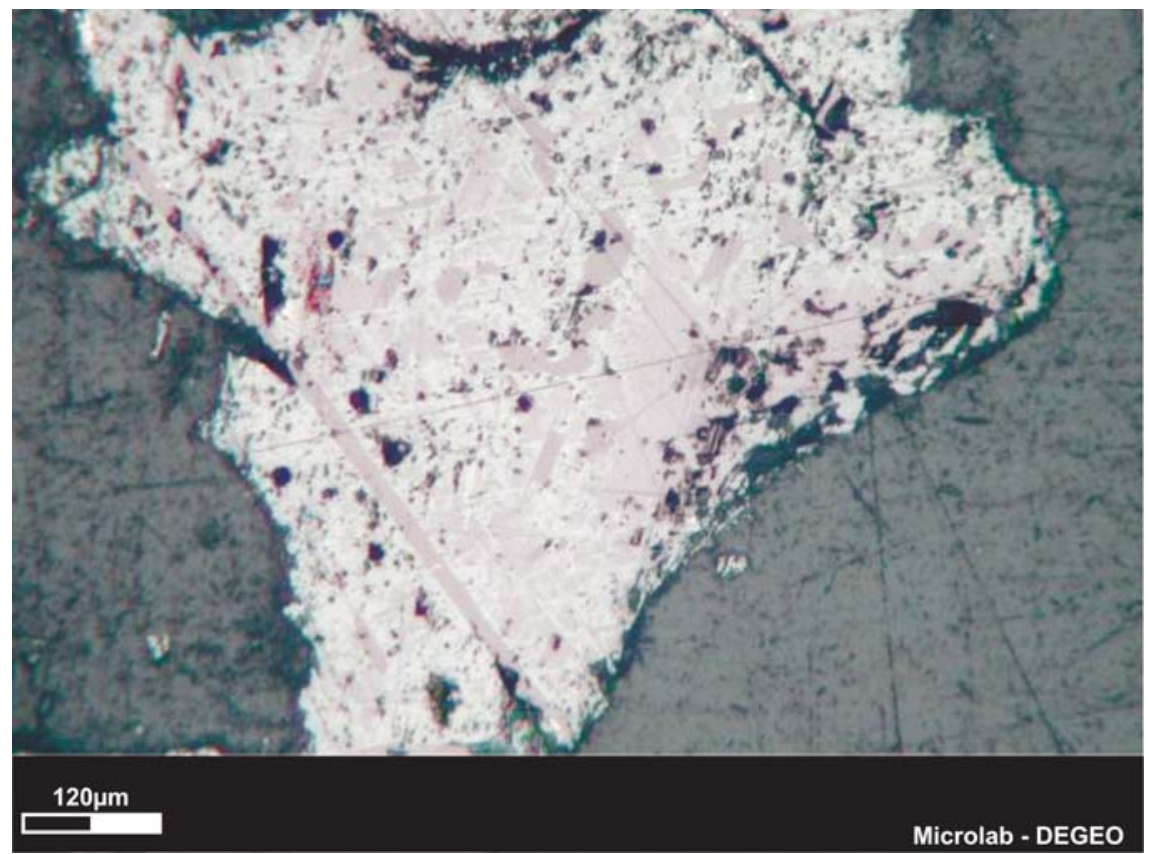

Figura 2 - Grão apresentando martitização e ilmenita intercrescida.

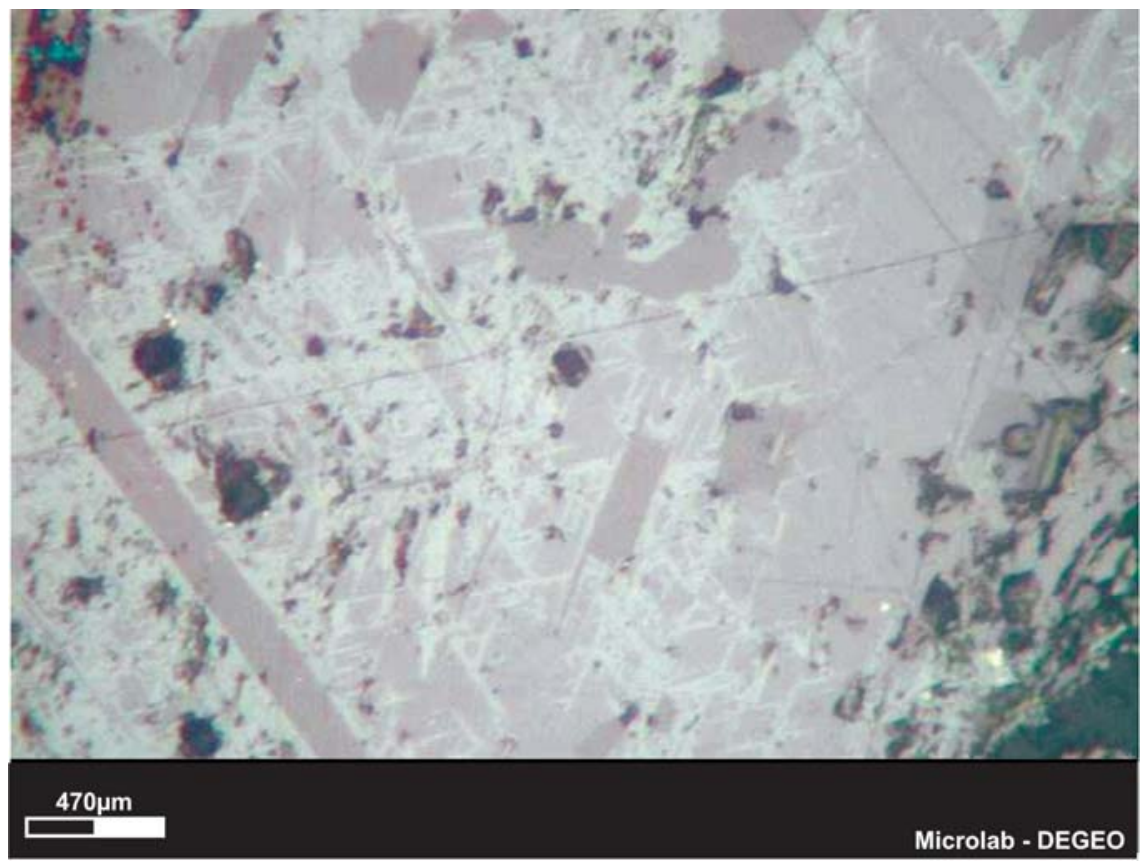

Figura 3 - Detalhe da fotomicrografia da Figura 2. 
Alysson A. Borges et al.

\subsection{Ensaios de concentração}

\subsubsection{Separação magnética}

Apesar de o material em estudo ser rejeito magnético de uma separação magnética industrial, nova separação magnética foi realizada e os resultados são apresentados na Tabela 3.

Vê-se que a recuperação metalúrgica do ferro ficou em torno de $97 \%$, resultado satisfatório. Destaca-se o teor $\mathrm{P}_{2} \mathrm{O}_{5}$ na fração não magnética, que está acima do valor da alimentação de $\mathrm{P}_{2} \mathrm{O}_{5}$ da usina, o que sugere estudo no sentido de se avaliar a eficiência do processo de separação magnética atualmente empregado.

\subsubsection{Ensaios de flotação}

As variáveis seguintes foram estudadas: tipo de coletor para apatita (hidrocol e amina) e processo de atrição da polpa antes do condicionamento da mesma. A Tabela 4 traz a seqüência de execução.

A Tabela 4 mostra que, nos ensaios 1,2,3,4, empregou-se o Hidrocol e, nos demais 5,6,7,8, empregou-se a amina e, nos ensaios 3,4,5,6, empregou-se processo de atrição. Na Figura 5, estão plotados ensaios versus teores de $\mathrm{P}_{2} \mathrm{O}_{5}$ no concentrado.

Destaca-se melhor desempenho do Hidrocol frente à amina na "remoção" do $\mathrm{P}_{2} \mathrm{O}_{5}$, não sendo sensível qualquer influência da etapa de atrição no desempenho da flotação.

\subsubsection{Lixiviação ácida}

O resultado da lixiviação está apresentado na Tabela 5, onde se tem o teor do fósforo antes da lixiviação (inicial) e pós-lixiviação (final), concluindo que o ácido acético extraiu 0,41 \% do fósforo e o ácido clorídrico extraiu 73,07 \% de tal elemento.

\section{Conclusão e considerações finais}

Através da caracterização tecnológica do material em estudo, verificou-se
Tabela 2 - Teor volumétrico estimado.

\section{Teor Volumétrico Estimado}

\begin{tabular}{c|c|c|c|c|c|c}
\hline \multicolumn{2}{l|}{} & \multicolumn{5}{c}{ \% dos Minerais } \\
\hline Fração \# & $\begin{array}{c}\text { Pontos } \\
\text { Contados }\end{array}$ & Ganga & Magnetita & Martita & Ilmenita & Goethita \\
\hline 35 & 150 & 11,24 & 58,2 & 20,66 & 7,19 & 2,68 \\
\hline 65 & 140 & 8,36 & 60,34 & 28,34 & 4,43 & 0,04 \\
\hline 100 & 170 & 5,6 & 62,61 & 25,68 & 3,60 & 0,37 \\
\hline 200 & 200 & 4,25 & 67,15 & 23,99 & 3,25 & 0,70 \\
\hline-400 & 200 & 1,08 & 68,71 & 24,05 & 2,63 & 3,45 \\
\hline
\end{tabular}

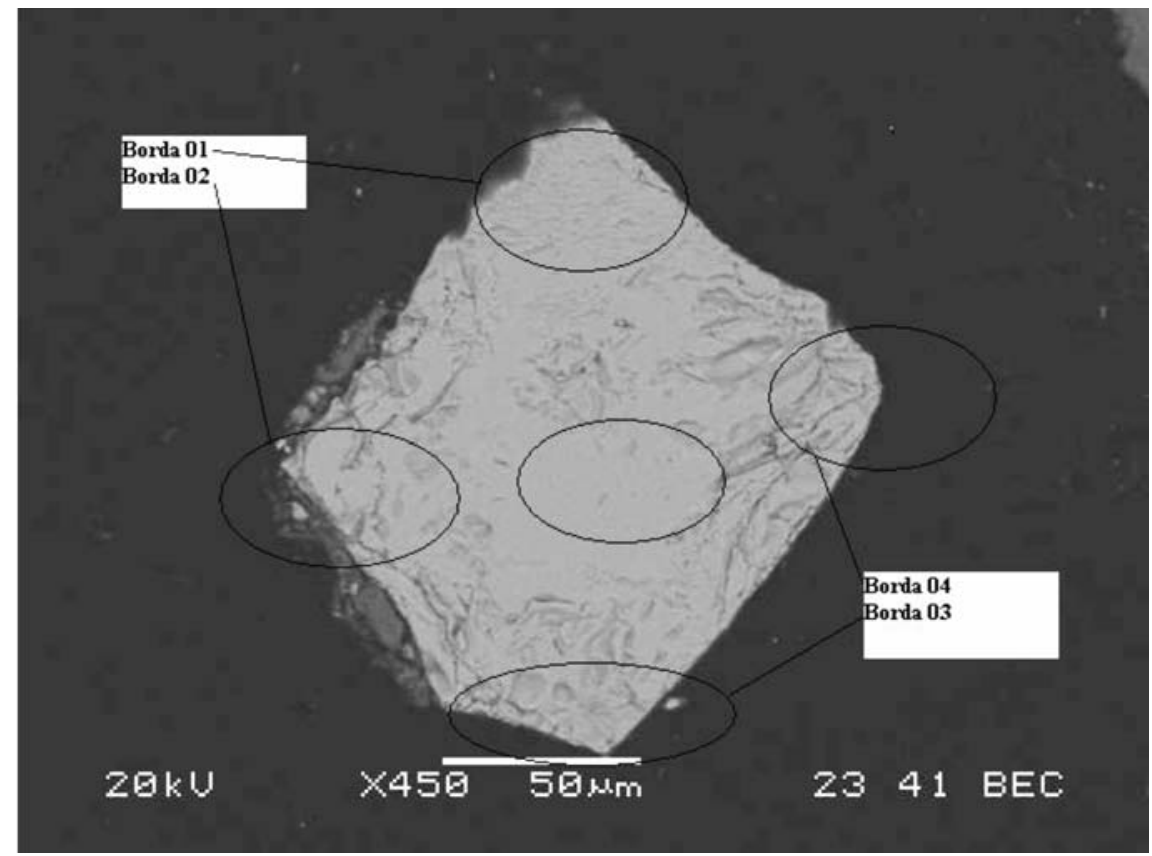

Figura 4 - Elétron-micrografia de partícula típica do material.

Tabela 3 - Resultados gerais da separação magnética.

\begin{tabular}{c|c|c|c}
\hline \multicolumn{2}{c|}{ Entradas e saídas } & \multicolumn{2}{c}{ Teores (\%) } \\
\hline & Massa (g) & $\mathbf{P}_{\mathbf{2}} \mathbf{O}_{\mathbf{5}}$ & $\mathbf{F e}_{\mathbf{T}}$ \\
\hline Aliemntação & 1050,00 & 1,62 & 78,86 \\
\hline Fração NÃo Magnética & 140,60 & 10,10 & 20,53 \\
\hline Fração Magnética & 881,00 & 0,61 & 87,02 \\
\hline \multicolumn{2}{c|}{ Balanço Metalúrgico } & $\mathbf{R e c} \mathbf{P}_{\mathbf{2}} \mathbf{O}_{\mathbf{5}}(\%)$ & $\mathbf{R e c ~ F e}_{\mathbf{T}}(\%)$ \\
\hline \multicolumn{2}{c|}{ Recuperação Mássica } & 13,39 & 83,9 \\
\hline \multicolumn{2}{c|}{ Recuperação Metalúrgica } & 66,35 & 96,81 \\
\hline
\end{tabular}


Tabela 4 - Seqüência de execução dos ensaios de flotação.

\begin{tabular}{c|c|c|c}
\hline Ensaio & Hidrocol & Amina & Atrição \\
\hline 1 & $\mathrm{X}$ & & \\
\hline 2 & $\mathrm{X}$ & & \\
\hline 3 & $\mathrm{X}$ & & $\mathrm{X}$ \\
\hline 4 & $\mathrm{X}$ & & $\mathrm{X}$ \\
\hline 5 & & $\mathrm{X}$ & $\mathrm{X}$ \\
\hline 6 & & $\mathrm{X}$ & $\mathrm{X}$ \\
\hline 7 & & $\mathrm{X}$ & \\
\hline 8 & & $\mathrm{X}$ & \\
\hline
\end{tabular}

que o mesmo é composto basicamente por magnetita, hematita e ilmenita, sendo a magnetita o mineral dominante e a hematita apresenta-se usualmente como martita.

A aplicação direta do material estudado na metalurgia é, atualmente, impraticável. Recomenda-se o aprofundamento dos estudos para adoção de rota, que, em princípio, inclua previamente separação magnética de baixa ou média intensidade, seguida de cominuição e flotação aniônica com sabão de ácido graxo. Reduzindo-se o fósforo para níveis aceitáveis, recomendase incorporação do concentrado a processos de sinterização e pelotização, com expectativa de ganhos energéticos típicos de $30 \%$, os quais se configuram como altamente atrativos. Também é conveniente detalhar o custo de lixiviação ácida de pelotas produzidas com esse material (após purificação), caso não se obtenha rota com suficiente seletividade entre apatita e magnetita.

Utilizações secundárias do rejeito magnético de Tapira naturalmente são possíveis, como, para se citarem dois exemplos, cama de filtragem em leitos de jigues centrífugos (após bitolamento) e como meio densificador em processos de afunda-flutua (como, por exemplo, na separação entre fluorita e quartzo). Já para sua utilização como meio densificador de lamas de sondagem, a quantificação de sua radiatividade natural será necessária, uma vez que sua provável ocorrência (reporte-se à ocorrência de elementos de terras-raras, comumente associados a elementos radiativos) pode inviabilizar esse uso, quando da adoção de perfilagem por gamametria, o que é regra na indústria de prospecção petrolífera. No

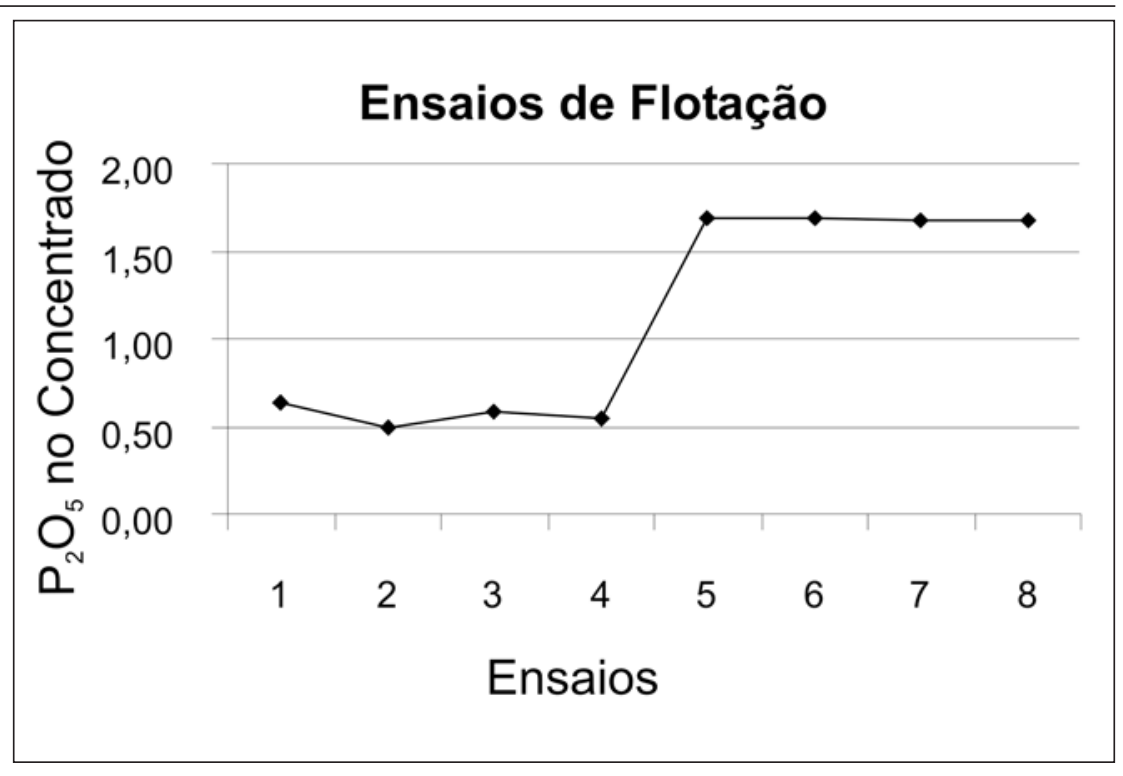

Figura 5 - Resultados dos ensaios de flotação.

Tabela 5 - Resultado da lixiviação ácida.

\begin{tabular}{c|c|c|c}
\hline \multicolumn{3}{|c|}{ Teor de P na Amostra } & \multirow{2}{*}{$\%$ de P Extraído } \\
\hline Ácido & Inicial & Final & \\
\hline Acético & 0,7368 & 0,7338 & 0,41 \\
\hline Clorídrico & 0,7368 & 0,1984 & 73,07 \\
\hline
\end{tabular}

presente trabalho, nenhuma medida do nível de radiatividade desse material foi feita.

\section{Agradecimentos}

Os autores agradecem a Fertilizantes Fosfatados S.A. - Fosfertil, pelas amostras e pelo suporte analítico concedido, bem como ao prof. Geraldo Magela da Costa, do Departamento de Química da UFOP, pelo seu apoio na espectroscopia Mössbauer; ao Departamento de Engenharia Geológica da UFOP pelo apoio nos trabalhos de microscopia eletrônica (Eng. Ney Sampaio) e pelas análises de fósforo no Laboratório de Geoquímica Ambiental.

\section{Referências bibliográficas}

1. ARAÚJO, L. A. Manual de siderurgia - produção. São Paulo: Arte e Ciências, 1997.

2. CLOUD, J.M. F, MANUEL. J.R. Fundamental investigations of differences in bonding mechanisms in iron ore sinter formed from magnetite concentrates and hematite ores. Powder Technology, n. 130, p. 393-399, 2003.

3. OLIVEIRA, E. R. Elaboração e caracterização de minipelotas utilizando resíduos siderúrgicos e pellet feed para posterior utilização na sinterização de minérios de ferro. Ouro Preto: PPGEM, UFOP, 2003. (Dissertação de Mestrado).

4. YANG, L.X, MATTHEWS, E. Sintering reactions of magnetite concentrates under various atmospheres. ISIJ International, v. 37, n.11, p.1051-1065, 1997.

5. ZULUAGA, L.M., BARRERO, C. A, DIAZ-TERÁN, J., JEREZ, A, RESTRUPO, J., MORALES A.L. Transformácion magnetita-hematita inducida termicamente. Revista Colombiana de Física, v. 33, n. 2, 2002.

Artigo recebido em 31/10/2006 e aprovado em 03/08/2007. 